Sage Advance Preprints

\title{
The Life Unites Us Campaign: A Novel Approach to Addressing Stigma against Opioid Use Disorder
}

\author{
Erika Bonnevie ${ }^{\mathrm{a}}$, Övgü Kaynak ${ }^{\mathrm{b}}$, Christopher R. Whipple ${ }^{\mathrm{b}}$, Weston S. Kensinger ${ }^{\mathrm{b}}$, Matthew Stefanko ${ }^{\mathrm{c}}$, \\ Courtney McKeon ${ }^{\mathrm{c}}$, Gary Mendell ${ }^{\mathrm{c}}$, Joe Smyser ${ }^{\mathrm{a}}$ \\ ${ }^{a}$ The Public Good Projects, Alexandria, VA, USA; ${ }^{b}$ The Douglas W. Pollock Center for Addiction \\ Outreach and Research at Pennsylvania State University, Harrisburg, Pennsylvania, USA; 'Shatterproof, \\ Norwalk, CT, USA
}

\begin{abstract}
BACKGROUND: Opioid use disorder (OUD) is a critical health issue in the United States. Pennsylvania has the third highest number of drug overdose deaths per year, with the COVID-19 pandemic worsening these trends. Stigmatizing beliefs toward OUD are associated with negative health outcomes, and there is a need for a larger evidence base on OUD stigma reduction strategies. This study reports on the creation and implementation of Life Unites Us, a digital media campaign which uses a collective impact framework to address OUD stigma reduction across Pennsylvania.

METHOD: Life Unites Us consists of various components, including: a general public media campaign which uses education and contact-based strategies; engagement with stakeholders and advocates in community-based organizations across the state; and a data sharing website to inform the public of previously unavailable OUD stigma statistics. Each campaign component contributes to the overall collective impact framework.

RESULTS: The campaign has partnered with 60 Community Based Organizations, 921 individuals receive the monthly email, and eleven influencers have posted 23 times and achieved over 13,000 engagements and a reach of 661,000 . The campaign hosted five webinars with 520 attendees and an overall $64.1 \%$ attendance rate.

CONCLUSIONS: This study fills a gap in the need for evidence-based digital interventions to address OUD stigma. The positive process metrics from the first six months suggest that this model may be an important addition to research on approaches to reduce OUD stigma.
\end{abstract}

\section{Introduction}

In 2018, over 10 million people in the United

States (U.S.) reported past year opioid misuse, defined as use of a prescription opioid in a way not directed by a doctor, or using heroin. ${ }^{1}$ Over the past twenty years, opioid overdose deaths in the U.S. have increased six-

\section{KEYWORDS}

Health communications, opioid use disorder, digital media campaigns, collective impact fold. ${ }^{2}$ In 2018, 46,802 people died of an opioid

overdose, and opioid-related deaths accounted for

almost $70 \%$ of all overdose deaths. ${ }^{3}$ Opioid use

disorder (OUD) is a particular problem in

Pennsylvania, which has the third highest number of 
drug overdose deaths per year, after California and Florida. ${ }^{4}$ Since 2018 , the state has seen their drug overdose deaths decrease by nearly $20 \%$; recently, however, overdose deaths have been on the rise. ${ }^{56}$ The COVID-19 pandemic appears to have worsened these trends statewide, with news stories and initial statistics pointing to a significant increase in overdoses: an estimated 4,909 drug overdose deaths have been reported from May 2019 - May 2020, an 11.1\% increase over the previous year, with $70 \%$ of these deaths due to opioids. ${ }^{78}$

Various factors have contributed to this recent increase in overdose deaths since the start of the COVID-19 pandemic, including decreased access to treatment and medication, increased social isolation, and a diversion of public attention away from the opioid epidemic and toward the COVID-19 pandemic. $^{9}$ ${ }^{10}$ While there have been efforts to provide telehealth and remote treatment options, those living with OUD have had less access to quality treatment since the beginning of the pandemic, particularly for those who want more intensive, group, or inpatient treatment. ${ }^{11} 12$ Stigma against OUD is one additional reason for negative opioid-related outcomes. The impacts of the COVID-19 pandemic on stigma remain an area in need of future study, with preliminary research suggesting that the pandemic has contributed to the further marginalization, and likely stigmatization, of people who use drugs. ${ }^{13}$ Addressing stigma against those living with OUD must be a key component of any effort to reduce opioid misuse and overdose. ${ }^{14}$

\section{Stigma and Opioid Use Disorder}

Stigmatizing beliefs toward OUD are associated with underutilization of treatment and medication, and increased risk of overdose. ${ }^{15} 1617$ Various types of stigma impact those living with OUD. Public stigma consists of an individual's negative beliefs toward OUD which are often driven by stereotypes, such as those living with OUD being dangerous or that addiction is a moral failing. ${ }^{18} 19$ Public stigma can become structural stigma when these public beliefs become codified into the functioning of societal structures, policies, and cultural norms. Structural stigma negatively impacts people with OUD across various areas, such as housing, employment, and healthcare. ${ }^{202122}$ Public and structural stigma can generate and reinforce self-stigma, which negatively impacts a person's self-perception, engagement in treatment, use of medications, and recovery. ${ }^{23} 2425$ Other types of stigma, such as associative or courtesy 
stigma, also impact those who associate with or who have loved ones living with addiction. ${ }^{26}$

There is a need for a larger evidence base on digital OUD stigma reduction strategies that are costeffective, scalable, and can quickly pivot to address changing circumstances which impact addiction. ${ }^{27} 2829$ Many of the digital or mass media-based strategies to date have focused on drug use prevention. These studies have largely been inconclusive, due to a variety of factors, including variability in type of intervention, outcome measures, and absence of theoretical frameworks. ${ }^{30}$ However, media campaigns have shown promise in improving other substance use behaviors. ${ }^{31}$ ${ }^{32}$ Some evidence has suggested that interventions to reduce substance use stigma should adopt multiple strategies at the outset, be longer-term, and focus on various aspects of attitudes toward people who use drugs. ${ }^{33}$ A larger evidence base around HIV and mental health stigma reduction strategies also show promise in the use of digital strategies to reduce public stigma, particularly when using knowledge building and firstperson narrative storytelling. ${ }^{34} 35363738$

Given the clear impact of stigma on health outcomes Pennsylvania's Department of Drug and Alcohol Programs (DDAP) has highlighted OUD stigma reduction as one of their key 2019-2022 strategic goals. ${ }^{39}{ }^{40}$ In reaction to DDAP's goals and the gap in the evidence base for digital approaches, The Life Unites Us campaign was started in September 2020 as an effort to address OUD stigma across Pennsylvania. The campaign's theoretical foundations are built upon the collective impact framework, which focuses on creating long-term collaborations to promote sustained change. The collective impact model has shown promise in addressing and preventing addiction. ${ }^{4142} 43$ It has also been used with success for other opioid misuse prevention and treatment, as well as other health behaviors including reducing sugary drink consumption, addressing mental health stigma, and improving nutrition in corner store retailers. ${ }^{44} 4546$ The collective impact framework consists of five core tenets (Figure 1): 1. Backbone organizations dedicated to overall coordination among various stakeholders and general leadership throughout the project; 2. A common agenda requiring that all participants agree on a vision for addressing a problem; 3 . Shared measurement systems representing agreed upon measures of success; 4. Mutually reinforcing activities designed to complement one another and the specific strengths of stakeholders; 5. Continuous communication to develop trust and open dialogue 
among backbone organizations and stakeholders

involved. ${ }^{47}$

Figure 1: Tenets of the Collective Impact Framework

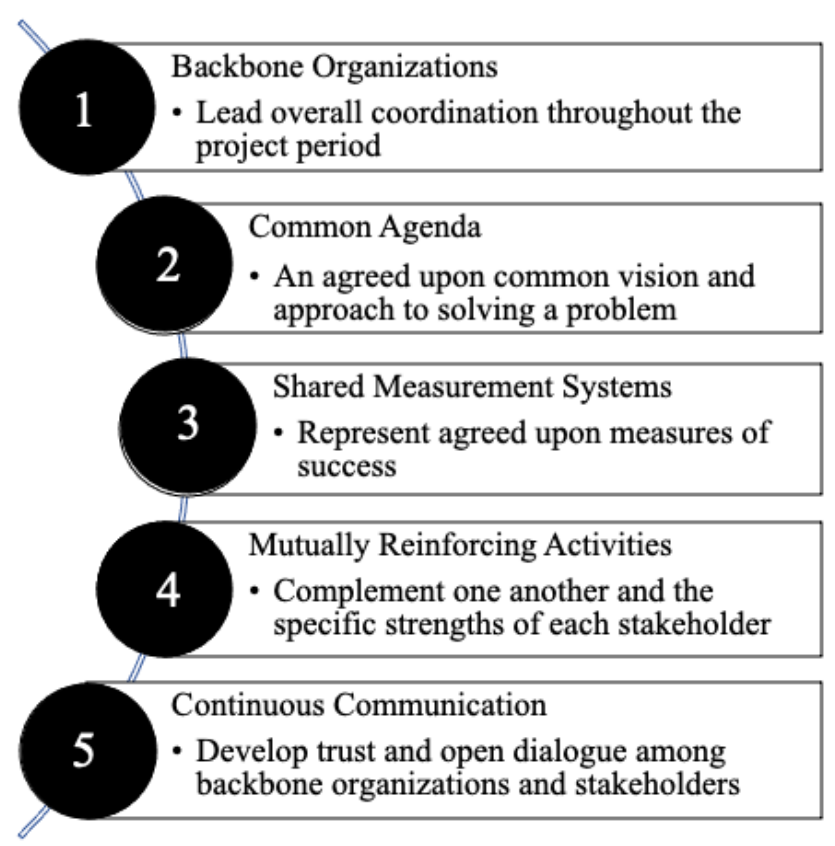

The Life Unites Us campaign employs a multifaceted strategy to deliver information. The campaign merges education-based, contact-based, and advocacy-based strategies that have each been highlighted for their promise in reducing stigma against mental health conditions and have been used in other stigma-related digital media campaigns. ${ }^{48} 49$ These three strategies are complementary and contribute to the collective impact framework. The education-based strategy focuses on educating the public about OUD, and correcting misinformation and stereotypes. Education-based strategies have shown success in increasing knowledge and awareness about an issue, though they are more effective when combined with contact-based strategies. ${ }^{50} 51$ They appear among the most promising strategies for reducing opioid overdose and misuse, though have been less studied for OUD stigma. ${ }^{52}$ The contact-based strategy raises awareness of OUD stigma through direct contact 
with people who have experienced addiction. ${ }^{53}$

Repeated contact through personal stories and testimonials have been shown to more effectively

reduce stigma. ${ }^{54}$ The advocacy-based strategy aims to engage and collaborate with individuals and organizations who are already interested in or engaged in work related to OUD. Advocacy strategies are often used with the aim of engaging those who are already interested in the topic. ${ }^{55}$

Life Unites Us applies lessons learned from these studies to address stigma against OUD in Pennsylvania. The campaign is a collaboration between three backbone organizations: public health nonprofit PGP (The Public Good Projects) who created and implement the media campaign and manage stakeholder involvement, national addiction nonprofit Shatterproof who support stakeholder management and provide overall guidance on addiction messaging, and subject matter experts at The Douglas W. Pollock Center for Addiction Outreach and Research at Pennsylvania State University, Harrisburg (Penn State Harrisburg) who manage data collection and sharing.

The aims of this study are to report on the creation and implementation of the Life Unites Us campaign, provide metrics on the first six months of its implementation in Pennsylvania, and comment on the strengths and potential future applications of the collective impact framework to reduce OUD stigma.

\section{Method}

Life Unites Us consists of the following components: 1) A digital media campaign using an education and contact-based strategy for the general public; 2) Engagement with stakeholders and advocates in community-based organizations across the state which work on various aspects related to addiction; 3) A data sharing website to inform the public of previously unavailable OUD stigma statistics within Pennsylvania.

\section{Digital Media Campaign Creation}

The Life Unites Us campaign content consists of testimonial videos from individuals who have experienced opioid addiction themselves, or individuals whose loved ones have experienced addiction, as well as static images that feature educational OUD stigma-related messages and quotes (See Supplemental File). Content messaging focuses on addressing the following key areas of OUD stigma reduction: 1) Treatment: Treatment and medication should be destigmatized, treatment, 
including medication-assisted therapy (MAT), can be effective; 2) Recovery: Recovery from OUD is probable; 3) Issues around morality: OUD is not a moral failing, people living with OUD are trustworthy and not more dangerous than the average person, people with OUD are not “junkies" ; 4) Susceptibility: Anyone can become addicted to opioids, regardless of demographic characteristics; 5) Medical definition: OUD is a chronic medical condition, like diabetes or heart disease, people do not decide to become addicted; and 6) Support: Increasing self-efficacy to support someone else living with addiction. Content is delivered across Facebook, Instagram and Twitter, with a YouTube page dedicated to hosting videos. Content is published 5-7 days each week across all platforms. Social media ads are delivered across platforms, at a budget of $\$ 600$ per month, per platform. Digital metrics for each platform are analyzed from Google Analytics on a monthly basis, and content is updated to reflect performance trends.

Through testimonial recruitment, PGP is building a diverse story library of people in recovery with OUD, close friends or family, and care providers who have either lived with OUD or are advocates for those with OUD. Testimonial participants are recruited in partnership with local community-based organizations (CBOs) who are already trusted by the community. CBOs ask members of their community to submit a video and/or photo, along with their story about how OUD has impacted them personally. CBOs provide potential participants with sample stories from other participants, a campaign overview, and personal submission guidance. If an individual expresses interest in becoming involved, a member of the PGP team reaches out to conduct an interview via virtual meeting software such as Zoom or Google Hangouts. Interviews are recorded, if the participant provides consent. Confidentiality and participant security are paramount throughout the process. All individuals who take part in this campaign are required to provide written consent for participation and are provided with a plain-language overview of what their participation entails, to ensure that they are fully aware of their involvement and how their testimonial will be used by the campaign and its partners. For individuals who share the story of a loved one's recovery, PGP also obtains consent from their loved one. The campaign and recruitment process are guided by both national and international codes of ethics, including the National Institute of Health's 
Code of Federal Regulations for working with

vulnerable populations, the World Health

Organization's publications on work with individuals

living with substance use, and other research on the topic. ${ }^{56575859}$ All project staff involved in outreach to potential participants and interviews for testimonial collection undergo an evidence-based virtual suicide prevention training. Prior to dissemination, testimonials are also reviewed by PGP's public health professionals who have experience working on research with vulnerable populations. For those who disclose current opioid usage, personally identifiable information is not included in content, including image and name, to protect the identity and rights of that individual. All testimonials are reviewed by subjects prior to dissemination on social media. Using this procedure, testimonial participants have not communicated any serious issues to PGP. Communications plans have also been developed to immediately address negative comments or feedback from the general public on the Life Unites Us social media campaigns. Any mildly negative comments are used as an opportunity to educate and reinforce key campaign messages; however posts that are explicitly or overtly vulgar or negative are immediately deleted, per the Life Unites Us social media policy (shor.by/CommentPolicy).

\section{Involvement of $C B O$ s and Stakeholders}

Through involvement with CBOs, local influencers, and stakeholders, Life Unites Us taps into the local knowledge and networks that exist across the state, addressing Tenets 2 and 4 of the collective impact model by setting a common agenda and focusing on mutually reinforcing activities.

Dedicated staff at PGP are responsible for coordination between CBOs and backbone organizations, ensuring that there is open dialogue among all project partners, addressing Tenet 5 of collective impact. This helps the campaign achieve a greater impact through collective work and partnership.

CBOs are provided with finalized testimonials free of charge, with or without campaign branding, and are curated to align with the population characteristics reached by the $\mathrm{CBO}$. CBOs in turn help to maximize campaign credibility and reach across Pennsylvania's geographic regions and diverse communities. CBOs can become involved in the campaign through multiple ways, including publicly endorsing the campaign with their logo on the 
campaign site, sharing information about the

campaign through digital media and professional

networks, sharing testimonials or campaign content

with their constituents, connecting PGP with

individuals interested in participating in the

campaign, facilitating connections with additional

stakeholders, participating in trainings, and informing

the campaign by sharing community insights and

needs.

Local influencers are recruited through a

combination of influencer recruitment software, and

recommendations from CBOs. Influencers are invited

to participate in the campaign by posting about OUD

stigma and the campaign on their own social media

accounts. Influencers are provided with guidance

from PGP on specific health messages to include in

their social media copy, to ensure the accuracy of

messages and that they align with the campaign's

overall goals. Influencers also encourage their

followers to visit the campaign social media accounts

and website (lifeunitesus.com). PGP staff are

available to provide guidance and support if

influencers receive any negative feedback or

comments from their followers; however this has not

happened.
To engage other local stakeholders, a

Community Impact Committee was formed to engage the recovery community in campaign

implementation. The committee consists of four individuals in recovery from a variety of

backgrounds, including county and nonprofit leaders

in their areas. The committee meets quarterly to

provide feedback and local insights to guide

implementation, and are invited to bi-weekly project

status meetings. The committee allows for a

dedicated feedback loop and ensures that local voices

are being heard and reflected in messaging.

Finally, other stakeholders can sign up to

receive monthly campaign updates and invitations to

online learning events and webinars. PGP,

Shatterproof, and the Douglas W. Pollock Center for

Addiction Outreach and Research lead monthly

webinars on topics identified by CBOs as important

for their capacity building. Webinars are recorded as

virtual seminars over Zoom. Webinar topics are

chosen based on the expressed needs of CBOs and

are developed and delivered by practitioners and

scholars working in the field of addiction. The 45-

minute sessions combine education and outreach by

providing CBOs with the opportunity to connect, ask questions, and provide feedback. 


\section{Public Data Sharing Website}

The public data sharing component of Life

Unites Us establishes a shared measurement system using agreed upon measures of public health indicators, addressing Tenet 3 of the collective impact model. Consistent data collection and measurement ensures that efforts are aligned, and all involved parties hold each other accountable throughout the project. ${ }^{60}$ The data are collected and displayed on a website

(padashboard.lifeunitesus.com) to provide stakeholders, CBOs, and the general public with relevant information related to the opioid epidemic. The website contains the following components: 1) data indicators; 2) results from a baseline survey about OUD stigma; 3) a map of CBOs across the state, and 4) a repository of recorded webinars. The website was developed by the Institute of State and Regional Affairs (ISRA) at Penn State Harrisburg and was built using technology from ArcGIS, Tableau, SQL database and Qualtrics survey software. Specific information about website components is below.

Data Indicators: Data indicator charts were built using public data provided by the Commonwealth of Pennsylvania and other organizations. Charts are paired with information from literature reviews and other primary and secondary data to contextualize stigma within four specific sectors examined. Sectors include: first responders, medical providers, institutions, (government, politicians, employers, criminal justice) and social networks. Website users can explore Pennsylvania-specific data and narratives related to each of these sectors.

Results from baseline survey: As part of the formal evaluation of Life Unites Us, three crosssectional surveys will be delivered across the state. Surveys are built and analyzed using Qualtrics data survey tools. A baseline survey occurred precampaign implementation, with two subsequent surveys occurring approximately six and twelve months after campaign launch. Each survey round includes 1,000 adults in Pennsylvania, with questions focusing on attitudes and experiences relating to opioid use, and public/ self/ structural stigma related to OUD. A quota-based invitation system is used to produce results that are representative of Pennsylvania's population by region and, separately, by age/sex combined categories. Data then are weighted to ensure representativeness by race, ethnicity, educational attainment, Department of 
Health region, and urban/rural status, in addition to age and gender. Data are imported into Tableau Desktop 2020, and separate paths are created in the dashboard, allowing users to view topical narratives or to explore data dynamically, depending on a user's interests. To date, the public data sharing website contains baseline survey results, and will be updated after the six- and twelve-month surveys, to present statewide trends over time. To protect the privacy of survey respondents, visuals are suppressed when selected filters result in fewer than 30 responses. In addition, only narrative level views are created for questions with few respondents (e.g., questions asked only of respondents who indicated present or past substance or opioid use disorder). Future studies will use the three cross-sectional surveys as an evaluative tool to measure campaign effectiveness. The survey protocol has been reviewed and deemed to be exempt by the Institutional Review Board at Penn State Harrisburg.

CBO Map: The CBO map presents the first centralized list of addiction-related CBOs operating in Pennsylvania. Data for the map were collected through a survey distributed to CBOs across the state, which asked them to provide their physical address, contact person, phone number, website, and counties served. CBO data are presented in a map generated using ESRI ArcGIS spatialization tools, allowing users to locate organizations near them.

Webinars: Each webinar hosted by Life Unites Us is recorded and uploaded to the public data sharing website. The website contains information about each webinar, including an overview and the webinar aims, and downloadable materials when relevant.

\section{Results}

Campaign and Digital Metrics

A total of 95 video testimonials have been collected during the first six months of campaign implementation. Digital metrics showed a total of 755 followers across the Life Unites Us social media pages (582 Facebook; 108 Instagram; 65 Twitter). Average monthly impressions were highest on Facebook $(239,416)$, followed by Instagram $(104,244)$ and Twitter $(6,440)$. Similarly, average daily reach was highest on Facebook $(6,925)$, followed by Instagram $(3,245)$, and average monthly engagements and video views were by far highest on Facebook $(3,472$ engagements; 316,586 video views), followed by Instagram (58 engagements; 850 video views), and 
Twitter (110 engagements; 1,141 video views). Since month. Website visitors spent an average of 2 minutes the beginning of the campaign, there have been 2,826 on the site.

total website users, and an average of 565 users per

Table 1: Social Media and Website Metrics

\begin{tabular}{l}
\hline Social Media Metrics \\
\begin{tabular}{|l|c|c|c|}
\hline & Instagram & Facebook & Twitter \\
\hline Average Monthly Impressions & 104,244 & 239,416 & 6,440 \\
\hline Average Daily Reach* & 3,245 & 6,925 & N/A \\
\hline Average Monthly Engagements** & 58 & 3,472 & 110 \\
\hline Video Views & 850 & 316,586 & 1,141 \\
\hline
\end{tabular}
\end{tabular}

\begin{tabular}{l|l}
\hline Website Metrics & Year 1 \\
\hline Total users (unique) & 2,826 \\
\hline Average Users / Month & 565 \\
\hline Total sessions (not unique) & 4,113 \\
\hline Total unique page views & 1,631 \\
\hline Average time on site & $2: 02$ \\
\hline Average Monthly Ad Budget & $\$ 600$ \\
\hline
\end{tabular}

*Twitter does not calculate reach metrics

** Engagements include likes, comments, shares, video views or post clicks

\section{Partnership Metrics}

The campaign has partnered with a total of influencers have posted 23 times ( 22 times on 60 Community Based Organizations (CBOs), and a Instagram, and 1 time on Twitter), and have total of 921 individuals have signed up to receive achieved over 13,000 engagements and a reach of the Life Unites Us monthly email. Eleven 661,000 . In the first six months of campaign 
implementation, Life Unites Us hosted five

webinars, attracting a total of 811 sign-ups and 520

attendees, for an overall $64.1 \%$ attendance rate.

Attendees have represented all six regions of
Pennsylvania. In general, attendance at the

webinars has increased over time, with the last three webinars attracting a majority of attendees

(Table 2).

Table 2: Webinar Metrics

\begin{tabular}{|l|l|l|l|}
\hline $\begin{array}{l}\text { Webinar } \\
\text { Month }\end{array}$ & Title & \multicolumn{1}{|c|}{ Topic } & $\begin{array}{l}\text { Number of } \\
\text { Attendees }\end{array}$ \\
\hline September & $\begin{array}{l}\text { Life Unites Us } \\
\text { Launch }\end{array}$ & $\begin{array}{l}\text { How a contact-based strategy can reduce OUD } \\
\text { stigma, meet the team behind the campaign, learn } \\
\text { about partnering with the campaign to support } \\
\text { current work CBOs are doing }\end{array}$ & 50 \\
\hline October & $\begin{array}{l}\text { Data-Driven } \\
\text { Decision Making }\end{array}$ & $\begin{array}{l}\text { Demonstrating how using Life Unites Us Opioid } \\
\text { and Substance Use Disorder Stigma Reduction } \\
\text { Campaign Dashboards } \\
\text { (padashboard.lifeunitesus.com) can enhance the } \\
\text { work being done by organizations, and how to find, } \\
\text { interpret and use data. }\end{array}$ & 23 \\
\hline November & $\begin{array}{l}\text { Advocating for } \\
\text { Addiction Reform }\end{array}$ & $\begin{array}{l}\text { Contacting state and federal representatives, } \\
\text { effective ways to advocate, provide updates on } \\
\text { current legislation to advance addiction reform }\end{array}$ & 94 \\
\hline December & $\begin{array}{l}\text { Pandemic } \\
\text { Paradigms: } \\
\text { Providing Services } \\
\text { Through the } \\
\text { Holiday Season }\end{array}$ & $\begin{array}{l}\text { Outlining the challenges presented by COVID-19 } \\
\text { as it relates to community-based recovery-focused } \\
\text { organizations, gaining insight into how to address } \\
\text { pandemic-related challenges in work }\end{array}$ & 115 \\
\hline January & $\begin{array}{l}\text { Drugs, Stigma, } \\
\text { and Policy: How } \\
\text { Language Drives } \\
\text { Change }\end{array}$ & $\begin{array}{l}\text { Examine the unique position language has on } \\
\text { stigma and why words matter. }\end{array}$ & 238 \\
\hline
\end{tabular}

\section{Conclusion}

The Life Unites Us campaign represents a novel approach to addressing OUD stigma. The campaign applies education, contact, and advocacy-based stigma reduction strategies to the collective impact model to create an approach that is guided by best practices which have shown 
promise in stigma reduction. Process metrics

from the first six months of implementation

suggest that the model can be successfully

applied, even within the COVID-19 pandemic

context. With almost 100 testimonials submitted,

high digital metrics and engagement particularly

on Facebook, and steadily increasing $\mathrm{CBO}$

involvement, we feel that the approach has been

well-received to date.

Engaging stakeholders around a common

agenda is a core aspect of Life Unites Us. By

creating and strengthening a network of CBOs

and individuals who are already working on the

issue, the campaign builds up the work currently

being done. These stakeholders are also critical in

informing testimonial gathering, and helps the

campaign ensure that messaging will resonate

and is reactive to local realities. Working with

partners to disseminate campaign content helps

keep the campaign hyperlocal and rooted in what

is happening on a county-by-county basis. This

has been particularly critical during the COVID-

19 pandemic, when CBOs have been key in

providing local insights into ways that addiction

is being experienced on-the-ground. In turn, this

information has helped to shift specific strategies and messaging to ensure that the campaign is

remaining timely and relevant amidst frequently

changing circumstances brought on by the

pandemic. Finally, with over 500 attendees at

Life Unites Us webinars and an overall

attendance rate of $64 \%$, it appears that when

engaged, organizations are motivated to

collaborate and learn from each other and from

health experts - even at a time when many are

likely overburdened and stretched for resources.

This suggests that the campaign is filling a needs gap among CBOs.

The public data sharing website provides

another way to support local efforts to understand and address OUD stigma. Timely sharing of local public health data, incorporating clinical, community, and individual monitoring data, supports coordinated and effective public health responses, and helps track OUD risk, identification, treatment, and recovery. ${ }^{61} 62$ Changing OUD stigma requires coordinated advocacy, proactive education, investment from community members and stakeholders, and support from local stakeholders such as law enforcement and local government. ${ }^{63}$ By providing access to unique and hyper localized 
data and information on OUD stigma, the

campaign provides an easy way to aggregate and share digestible information.

The digital aspect of the Life Unites Us approach provides benefits that have been immediately apparent throughout the first six months of implementation. The campaign's ability to be flexible and to pivot based on types of content that are performing well at the moment have allowed content to be reactive to events on the ground as they happen. The Life Unites Us approach also has substantial cost implications, with the campaign able to accomplish its goals while working on a fraction of a budget that is typically needed for health campaigns using more traditional or print media approaches. ${ }^{64}{ }^{65}$ It is also important to note that all of the aforementioned work has been accomplished in less than one year, with project planning beginning in April 2020 and the public campaign launching in September 2020. Combined with the promising digital metrics, number of testimonials gathered, and engagement of CBOs, we feel that this method holds promise in reducing OUD stigma statewide.
It is also important to note that of the testimonials that have been posted to the campaign, there have been no reports of adverse reactions from participants; anecdotally, there have been two instances in which a negative comment on the social media page was removed. This is notable because while a contact-based approach has been shown to improve public stigma, it may also have the effect of empowering those who tell their stories. ${ }^{66}{ }^{67}$ Negative comments on social media can have a detrimental effect on mental health $;{ }^{68}$ it is therefore encouraging that this was not a challenge faced by the campaign. The collective impact aspect of the Life Unites Us approach may also compel those who participate to feel as if they are part of a larger community movement. This may have the dual impact of reducing OUD stigma among the general public, and those with personal experiences with addiction. Future research will focus on the effectiveness of this approach at reducing OUD stigma. A scientific evaluation is being conducted by Penn State Harrisburg to monitor changes in public, self- and associative stigma across Pennsylvania. Data will be available in late 2021, after the first year of implementation. 


\section{Conclusions}

This study fills a gap in the need for digital interventions to address OUD stigma. Through its use of the collective impact model and evidence-based stigma reduction strategies, the Life Unites Us campaign focuses on empowering individuals and their communities using their own language and spokespeople. The campaign uses the collective impact model to break down silos, connecting the backbone organizations with CBOs and local individuals willing to share their stories. Capacity building helps CBOs stay engaged with the campaign and fills gaps in their knowledge and capabilities. Though Life Unites Us relies on its firm roots in the community, its digital strategies also allow the campaign to be flexible and easily scalable. The positive process metrics that have been shown in the first six months of implementation lead us to believe that this model may be an important addition to research on approaches to reduce OUD stigma. 


\section{References}

\footnotetext{
${ }^{1}$ Bose, J., Hedden, S.L., Lipari, R.N., Park-Lee, E. and Tice, P., 2018. Key substance use and mental health indicators in the United States: Results from the 2017 National Survey on Drug Use and Health (HHS Publication No. SMA 18-5068, NSDUH Series H-53). Rockville, MD: Center for Behavioral Health Statistics and Quality. Substance Abuse and Mental Health Services Administration.

${ }^{2}$ Centers for Disease Control and Prevention, 2018. Overview of the drug overdose epidemic: Behind the numbers. National Center for Injury Prevention and Control, Division of Unintentional Injury Prevention.

${ }^{3}$ Wilson, N., 2020. Drug and opioid-involved overdose deaths-United States, 2017-2018. MMWR. Morbidity and Mortality Weekly Report, 69.

${ }^{4}$ Centers for Disease Control and Prevention, 2021. Drug Overdose Mortality by State. Accessed on March 30, 2021. https://www.cdc.gov/nchs/pressroom/sosmap/drug_poisoning_mortality/drug_poisoning.htm ${ }^{5}$ Ahmed, R, 2020. COVID-19 pandemic contributes to increase in overdose deaths, state health officials say. Accessed on March 30, 2021. https://www.penncapital-star.com/covid-19/covid19-pandemic-contributes-to-increase-in-overdose-deaths-state-health-officials-say/

${ }^{6}$ American Medical Association, 2021. Issue brief: Reports of increases in opioid- and other drug-related overdose and other concerns during COVID pandemic. Accessed on March 30, 2021. https://www.ama-assn.org/system/files/2020-12/issue-brief-increases-in-opioid-relatedoverdose.pdf

${ }^{7}$ NIDA. 2020. Pennsylvania: Opioid-Involved Deaths and Related Harms. Accessed on March 1, 2021. https://www.drugabuse.gov/drug-topics/opioids/opioid-summaries-by-state/pennsylvaniaopioid-involved-deaths-related-harms

${ }^{8}$ Ahmad, F.B., Rossen, L.M., and Sutton, P., 2020. Provisional drug overdose death counts. National Center for Health Statistics.

9 D'Onofrio, G., Venkatesh, A. and Hawk, K., 2020. The adverse impact of COVID-19 on individuals with OUD highlights the urgent need for reform to leverage emergency departmentbased treatment. NEJM Catalyst Innovations in Care Delivery.

${ }^{10}$ Silva, M.J. and Kelly, Z., 2020. The escalation of the opioid epidemic due to COVID-19 and resulting lessons about treatment alternatives. Am J Manag Care, 26(7), pp.e202-e204.

${ }^{11}$ Crowley, D. and Delargy, I., 2020. A national model of remote care for assessing and providing opioid agonist treatment during the COVID-19 pandemic: a report. Harm Reduction Journal, 17(1), pp.1-5.

${ }^{12}$ Hughto, J.M., Peterson, L., Perry, N.S., Donoyan, A., Mimiaga, M.J., Nelson, K.M. and Pantalone, D.W., 2020. The provision of counseling to patients receiving medications for opioid use disorder: Telehealth innovations and challenges in the age of COVID-19. Journal of Substance Abuse Treatment, 120, p.108163.

13 Jenkins, W.D., Bolinski, R., Bresett, J., Van Ham, B., Fletcher, S., Walters, S., Friedman, S.R., Ezell, J.M., Pho, M., Schneider, J. and Ouellet, L., 2020. COVID-19 During the Opioid Epidemic-Exacerbation of Stigma and Vulnerabilities. The Journal of Rural Health: Official Journal of the American Rural Health Association and the National Rural Health Care Association.
} 
14 Tsai, A.C., Kiang, M.V., Barnett, M.L., Beletsky, L., Keyes, K.M., McGinty, E.E., Smith, L.R., Strathdee, S.A., Wakeman, S.E. and Venkataramani, A.S., 2019. Stigma as a fundamental hindrance to the United States opioid overdose crisis response. PLoS Medicine, 16(11), p.e1002969.

${ }^{15}$ Allen, B., Nolan, M.L. and Paone, D., 2019. Underutilization of medications to treat opioid use disorder: What role does stigma play?. Substance Abuse, 40(4), pp.459-465.

${ }^{16}$ Moore, M.D., Ali, S., Burnich-Line, D., Gonzales, W. and Stanton, M.V., 2020. Stigma, Opioids, and Public Health Messaging: The Need to Disentangle Behavior From Identity. American Journal of Public Health, 110(6), pp.807-810.

${ }^{17}$ Latkin, C.A., Gicquelais, R.E., Clyde, C., Dayton, L., Davey-Rothwell, M., German, D., Falade-Nwulia, S., Saleem, H., Fingerhood, M. and Tobin, K., 2019. Stigma and drug use settings as correlates of self-reported, non-fatal overdose among people who use drugs in Baltimore, Maryland. International Journal of Drug Policy, 68, pp.86-92.

18 Janulis, P., Ferrari, J.R. and Fowler, P., 2013. Understanding public stigma toward substance dependence. Journal of Applied Social Psychology, 43(5), pp.1065-1072.

${ }^{19}$ Morone, J.A., 1997. Enemies of the people: the moral dimension to public health. Journal of Health Politics, Policy and Law, 22(4), pp.993-1020.

${ }^{20}$ Pescosolido, B.A., Martin, J.K., Lang, A. and Olafsdottir, S., 2008. Rethinking theoretical approaches to stigma: A framework integrating normative influences on stigma (FINIS). Social Science \& Medicine, 67(3), pp.431-440.

${ }^{21}$ McGinty, E.E. and Barry, C.L., 2020. Stigma reduction to combat the addiction crisisdeveloping an evidence base. N Engl J Med, 382(14), pp.1291-1292.

22 Shatterproof, 2020. A movement to end stigma. Accessed on March 30, 2021. https://www.shatterproof.org/sites/default/files/2020-07/A-Movement-to-End-AddictionStigma.pdf

${ }^{23}$ Dole, V.P. and Nyswander, M.E., 1980. Methadone maintenance: a theoretical perspective. NIDA Research Monograph, 30, p.256.

${ }^{24}$ Cheng, C.M., Chang, C.C., Wang, J.D., Chang, K.C., Ting, S.Y. and Lin, C.Y., 2019. Negative impacts of self-stigma on the quality of life of patients in methadone maintenance treatment: the mediated roles of psychological distress and social functioning. International Journal of Environmental Research and Public Health, 16(7), p.1299.

${ }^{25}$ Hammarlund, R., Crapanzano, K.A., Luce, L., Mulligan, L. and Ward, K.M., 2018. Review of the effects of self-stigma and perceived social stigma on the treatment-seeking decisions of individuals with drug-and alcohol-use disorders. Substance Abuse and Rehabilitation, 9, p.115. ${ }^{26}$ Garg, R., Gupta, A. and Kundal, D., 2019. Comparison of impact of family stigma on quality of life among caregivers of male inpatients with alcohol and opioid use disorder. Industrial Psychiatry Journal, 28(2), p.278.

${ }^{27}$ Furlan, A.D., Carnide, N., Irvin, E., Van Eerd, D., Munhall, C., Kim, J., Li, C.M.F., Hamad, A., Mahood, Q. and MacDonald, S., 2018. A systematic review of strategies to improve appropriate use of opioids and to reduce opioid use disorder and deaths from prescription opioids. Canadian Journal of Pain, 2(1), pp.218-235.

${ }^{28}$ Lefebvre RC, Chandler RK, Helme DW, Kerner R, Mann S, Stein MD, Reynolds J, Slater $\mathrm{MD}$, Anakaraonye AR, Beard D, Burrus O. Health communication campaigns to drive demand for evidence-based practices and reduce stigma in the HEALing Communities Study. Drug and Alcohol Dependence. 2020 Dec 1;217:108338. 
${ }^{29}$ McGinty, E.E. and Barry, C.L., 2020. Stigma reduction to combat the addiction crisisdeveloping an evidence base. N Engl J Med, 382(14), pp.1291-1292.

${ }^{30}$ Allara, E., Ferri, M., Bo, A., Gasparrini, A. and Faggiano, F., 2015. Are mass-media campaigns effective in preventing drug use? A Cochrane systematic review and meta-analysis. BMJ Open, 5(9).

${ }^{31}$ Allen, J.A., Duke, J.C., Davis, K.C., Kim, A.E., Nonnemaker, J.M. and Farrelly, M.C., 2015. Using mass media campaigns to reduce youth tobacco use: a review. American Journal of Health Promotion, 30(2), pp.e71-e82.

32 Robert Wood Johnson Foundation, 2019. Mass media campagins against tobacco use. Accessed on March 30, 2021. https://www.countyhealthrankings.org/take-action-to-improvehealth/what-works-for-health/strategies/mass-media-campaigns-against-tobacco-use

33 Tostes, J.G.D.A., Dias, R.T., Reis, A.A.D.S., Silveira, P.S.D. and Ronzani, T.M., 2020. Interventions to reduce stigma related to people who use drugs: systematic review. Paidéia (Ribeirão Preto), 30.

34 The Public Good Projects (PGP), 2019. Action Minded: Reducing Mental Health Stigma Using Digital Media Campaigns. Accessed on March 30, 2021.

https://actionminded.org/files/action-minded-evaluation.pdf

${ }^{35}$ National Academies of Sciences, Engineering, and Medicine, 2016. Ending discrimination against people with mental and substance use disorders: The evidence for stigma change.

National Academies Press.

${ }^{36}$ Clement, S., Lassman, F., Barley, E., Evans-Lacko, S., Williams, P., Yamaguchi, S., Slade, M., Rüsch, N. and Thornicroft, G., 2013. Mass media interventions for reducing mental healthrelated stigma. Cochrane Database of Systematic Reviews, (7).

${ }^{37}$ Kerr, J.C., Valois, R.F., DiClemente, R.J., Carey, M.P., Stanton, B., Romer, D., Fletcher, F., Farber, N., Brown, L.K., Vanable, P.A. and Salazar, L.F., 2015. The effects of a mass media HIV-risk reduction strategy on HIV-related stigma and knowledge among African American adolescents. AIDS Patient Care and STDs, 29(3), pp.150-156.

${ }^{38}$ Daher, J., Vijh, R., Linthwaite, B., Dave, S., Kim, J., Dheda, K., Peter, T. and Pai, N.P., 2017. Do digital innovations for HIV and sexually transmitted infections work? Results from a systematic review (1996-2017). BMJ Open, 7(11), p.e017604.

${ }^{39}$ Enos, G., 2020. Pennsylvania sees stigma reduction as pivotal to improving treatment. Alcoholism \& Drug Abuse Weekly, 32(38), pp.1-8.

${ }^{40}$ Pennsylvania Department of Drug and Alcohol Programs, 2019. Pennsylvania Department of Drug and Alcohol Programs 2019 - 2022 State Plan. Accessed on March 30, 2021.

https://www.ddap.pa.gov/Documents/Agency\%20Reports/State\%20Plan\%20and\%20Annual\%2 0Reports/2019-2022\%20DDAP\%20State\%20Plan.pdf

${ }^{41}$ Knighton, A.J., Brunisholz, K.D., Reisig, K. and Nichols, L., 2018. Using a collective impact approach to prevent prescription opioid misuse, addiction, and overdose deaths. Quality Management in Healthcare, 27(4), pp.237-239.

${ }^{42}$ Brunisholz, K.D., Knighton, A., Sharma, A., Nichols, L., Reisig, K., Burton, J., Scovill, D., Tometich, C., Foote, M., Read, S. and Whittle, S., 2020. Trends in abstinence and retention associated with implementing a Medication Assisted Treatment program for people with opioid use disorders using a Collective Impact approach. Progress in Community Health Partnerships: Research, Education, and Action, 14(1), p.43. 
${ }^{43}$ Bonfine, N., Munetz, M.R. and Simera, R.H., 2018. Sequential intercept mapping: developing systems-level solutions for the opioid epidemic. Psychiatric Services, 69(11), pp.1124-1126.

${ }^{44}$ Bonnevie, E., Morales, O., Rosenberg, S.D., Goldbarg, J., Silver, M., Wartella, E. and Smyser, J., 2020. Evaluation of a campaign to reduce consumption of sugar-sweetened beverages in New Jersey. Preventive medicine, 136, p.106062.

${ }^{45}$ Flood, J., Minkler, M., Hennessey Lavery, S., Estrada, J. and Falbe, J., 2015. The collective impact model and its potential for health promotion: overview and case study of a healthy retail initiative in San Francisco. Health Education \& Behavior, 42(5), pp.654-668.

${ }^{46}$ Knighton, A.J., Brunisholz, K.D., Reisig, K. and Nichols, L., 2018. Using a collective impact approach to prevent prescription opioid misuse, addiction, and overdose deaths. Quality Management in Healthcare, 27(4), pp.237-239.

${ }^{47}$ Kania, J. and Kramer, M., 2011. Collective impact (pp. 36-41). FSG.

48 The Public Good Projects (PGP), 2019. Action Minded: Reducing Mental Health Stigma Using Digital Media Campaigns. Accessed on March 30, 2021. https://actionminded.org/files/action-minded-evaluation.pdf

${ }^{49}$ National Academies of Sciences, Engineering, and Medicine, 2016. Ending discrimination against people with mental and substance use disorders: The evidence for stigma change. National Academies Press.

${ }^{50}$ Griffiths, K.M., Carron-Arthur, B., Parsons, A. and Reid, R., 2014. Effectiveness of programs for reducing the stigma associated with mental disorders. A meta-analysis of randomized controlled trials. World psychiatry, 13(2), pp.161-175.

${ }^{51}$ Corrigan, P.W., Morris, S.B., Michaels, P.J., Rafacz, J.D. and Rüsch, N., 2012. Challenging the public stigma of mental illness: a meta-analysis of outcome studies. Psychiatric Services, 63(10), pp.963-973.

52 Furlan, A.D., Carnide, N., Irvin, E., Van Eerd, D., Munhall, C., Kim, J., Li, C.M.F., Hamad, A., Mahood, Q. and MacDonald, S., 2018. A systematic review of strategies to improve appropriate use of opioids and to reduce opioid use disorder and deaths from prescription opioids. Canadian Journal of Pain, 2(1), pp.218-235.

${ }^{53}$ Livingston, J.D., Milne, T., Fang, M.L. and Amari, E., 2012. The effectiveness of interventions for reducing stigma related to substance use disorders: a systematic review. Addiction, 107(1), pp.39-50.

54 Griffiths, K.M., Carron-Arthur, B., Parsons, A. and Reid, R., 2014. Effectiveness of programs for reducing the stigma associated with mental disorders. A meta-analysis of randomized controlled trials. World Psychiatry, 13(2), pp.161-175.

${ }^{55}$ National Academies of Sciences, Engineering, and Medicine, 2016. Ending discrimination against people with mental and substance use disorders: The evidence for stigma change. National Academies Press.

${ }^{56}$ Anderson, E. and McNair, L., 2018. Ethical issues in research involving participants with opioid use disorder. Therapeutic innovation \& regulatory science, 52(3), pp.280-284.

${ }^{57}$ McCall, J., Phillips, J.C., Estafan, A. and Caine, V., 2020. The patients have a story to tell: Informed consent for people who use illicit opiates. Nursing Ethics, 27(3), pp.666-672.

${ }^{58}$ U.S. Department of Health and Human Services, National Institutes of Health, 2021. Accessed on March 20, 2021. https://grants.nih.gov/policy/humansubjects/policies-andregulations/vulnerable-populations.htm 
${ }^{59}$ World Health Organization, 2021. Management of substance abuse. Accessed on March 20, 2021. https://www.who.int/substance_abuse/publications/en/

${ }^{60}$ Hanleybrown, F., Kania, J. and Kramer, M., 2012. Channeling change: Making collective impact work (pp. 56-78). FSG.

${ }^{61}$ Edelstein, M., Lee, L.M., Herten-Crabb, A., Heymann, D.L. and Harper, D.R., 2018. Strengthening global public health surveillance through data and benefit sharing. Emerging Infectious Diseases, 24(7), p.1324.

${ }^{62}$ Griffin, P.M., 2020. Engineering Approaches for Addressing Opioid Use Disorder in the Community. Annual Review of Biomedical Engineering, 22, pp.207-229.

${ }^{63}$ Childs, E., Biello, K.B., Valente, P.K., Salhaney, P., Biancarelli, D.L., Olson, J., Earlywine, J.J., Marshall, B.D.L. and Bazzi, A.R., 2021. Implementing harm reduction in non-urban communities affected by opioids and polysubstance use: A qualitative study exploring challenges and mitigating strategies. International Journal of Drug Policy, 90, p.103080.

${ }^{64}$ Allom, V., Jongenelis, M., Slevin, T., Keightley, S., Phillips, F., Beasley, S. and Pettigrew, S., 2018. Comparing the cost-effectiveness of campaigns delivered via various combinations of television and online media. Frontiers in Public Health, 6, p.83

${ }^{65}$ Strecher, V., 2007. Internet methods for delivering behavioral and health-related interventions (eHealth). Annu. Rev. Clin. Psychol., 3, pp.53-76.

${ }^{66}$ Paterno, M.T., Fiddian-Green, A. and Gubrium, A., 2018. Moms supporting moms: Digital storytelling with peer mentors in recovery from substance use. Health Promotion Practice, 19(6), pp.823-832.

${ }^{67}$ Ferrari, M., Rice, C. and McKenzie, K., 2015. ACE Pathways Project: therapeutic catharsis in digital storytelling. Psychiatric Services (Washington, DC), 66(5), pp.556-556.

${ }^{68}$ Naslund, J.A., Bondre, A., Torous, J. and Aschbrenner, K.A., 2020. Social media and mental health: Benefits, risks, and opportunities for research and practice. Journal of Technology in Behavioral Science, 5(3), pp.245-257. 